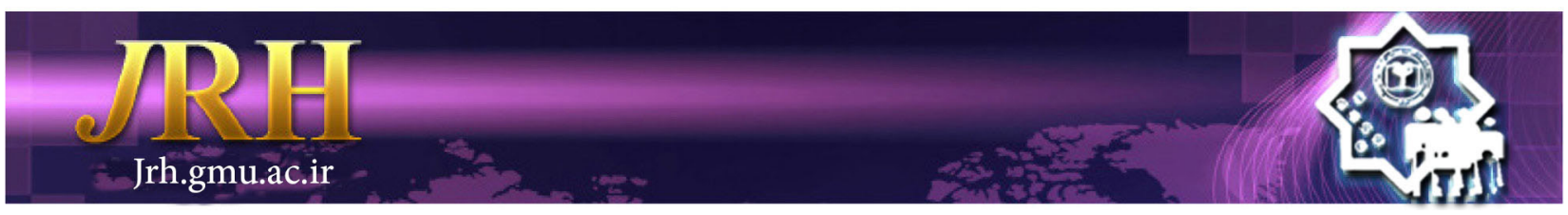

\title{
Predictors of intention to quit smoking among hospital male personnel
}

\author{
Sajjad Narimani ${ }^{1}$, Rabiollah Farmanbar ${ }^{2}$, Ehsan Kazemnejad Leyli ${ }^{3}$
}

\author{
Journal of Research \& Health \\ Social Development \& Health Promotion \\ Research Center \\ Vol. 9, No.2, Mar \& Apr 2019 \\ Pages: $140-146$ \\ DOI: $10.29252 /$ jrh. 9.2 .140 \\ Original Article
}

1. Correspondence to: Department of Nursing, School of Nursing, Ardebil University of Medical Sciences, Ardebil, Iran Email: sn_narimani@yahoo.com

2. Department of Health Education and Promotion, School of Health, Social Determinants of Health Research Center, Guilan University of Medical Sciences, Guilan, Iran

3. Department of Biostatistics, Road Truma Research Center, Guilan University of Medical Science, Guilan, Iran

Received: 1 Jan 2013

Accepted: 5 Oct 2013

How to cite this article: Narimani $S$, Farmanbar R, Kazemnejad Leyli E. Predictors of intention to quit smoking among hospital male personnel. $J$ Research \& Health2019; 9(2): 140- 146

\begin{abstract}
Smoking is the most preventable cause of premature death in the world and its disadvantages impose heavy financial burden on the health system. Among the behavioral models of health education, the most applicable one in smoking cessation is Transtheoretical Model (TTM). This study aimed to detect the predictors of smoking cessation among hospital male personnel. The participants were 200 current and former smokers Personnel working at four hospitals. The instruments included decisional balance scale, self-efficacy scale, processes of change scale (behavioral and experiential), and stages of change which were completed by self-report. Descriptive statistics analysis showed that $66.5 \%$ of participants were located in the earlier stages of change. Bivariate spearman correlations showed that self-efficacy, processes of change and decisional balance were significantly correlated with the stage of change. Besides, ordinal regression revealed that experiential processes of change, self-efficacy and behavioral processes were the strongest predictors for the change stages of smoke cessation. The current study revealed that the readiness to quit smoking is significantly predicted by the mechanisms of self-efficacy and the process of change such as environment reevaluation, stimulus control and counter conditioning, which can lead to positive progress in the change stages of smoke cessation. The findings of this study showed that using TTM for smoking cessation would be very effective in improving readiness to quit smoking among hospitals personnel.
\end{abstract}

Keywords: Health Risk Behaviors, Group Psychotherapy, Reality Therapy

\section{Introduction}

Poor lifestyle is a risk factor for the incidence of chronic diseases. One of the most important factors affecting lifestyle is smoking. In fact, smoking in the workplace affects the smoker's health and income. Literature review shows that being exposed to second-hand tobacco smoke is a potential source of the same illnesses of smokers making workplace air polluted and leading occupational health problems. This problem would be more acute, in the case of individual's vulnerability due to some circumstances, for example asthma or pregnancy. Fire and explosions could often be avoided if smoking is prohibited. This study seriously deals with the adoption of appropriate measures to concentration loss during smoking 
and the potential conflict between smokers and non-smokers [1].

According to the World Health Organization (WHO) report in 2011, one billion and three hundred million people are cigarette smokers around the world, out of which $84 \%$ are living in developing countries. According to the healthy Plan , $27.3 \%$ of men and $3.4 \%$ of women were smokers, and $66.3 \%$ of people had started smoking at the age of 15-24 years-old in Iran, 2012 [2].

Smoking is something that most of us call it a 'bad habit' and certainly we do so for a good reason. The disadvantages of smoking are numerous and well-known. The European commission of health has declared that tobacco use is the strongest cause of preventable death in the European Union (EU) by itself. The awareness from the negative effects of smoking has increased, however, approximately one third of the European population continue to smoke [3].

Workplace smoking would be a serious safety and health hazard which causes confliction. A smoke-free work environment under the International Labor Organization (ILO) provides a healthy and safe workplace. Among 16 countries of the WHO Eastern mediterranean region, Iran stands in sixth place after Oman, United Arabic Emirates, Saudi Arabia, Sudan and Bahrain ranked in workplace smoking. Moreover, Iran's world rank, is thirty-third with the average of $26 \%$ smokers [4].

Annually, smoking leads to 5 million deaths and it is estimated that this figure reach to 10 million by 2030 . It is notable that, $80 \%$ of premature deaths occurs in low-income and developing countries [5]. The predictive factors of quit smoking, include a comprehensive part of antitobacco process [6].

A new model of smoking behavior change which has recently emerged addresses the following issues -failure in patient admission, physicians' disappointment, low rates of success, cessation and quick resume. Prochaska and DiClemente described a framework in which individuals move through stages to change their behavior according to their motivation.
The Transtheoretical Model (TTM) contains five stages: precontemplation, contemplation, determination, action, and maintenance. This model has been validated and adopted by a variety of addictive and healthy related behaviors and has been effectively used in smoking cessation. Accordingly, this model is applied for assessing the stage of change at baseline and follow-up in order to explore whether individuals have experienced a change in their readiness to quit smoking or not. Other constructs of this model are self-efficacy, decisional Balance and process of change. The relationship of this constructs with the stage of change determinates the behavioral changes among target population [7].

Therefore, for developing or designing successful cessation programs which address smokers' specific needs in different stages of change, it is important to study the stage of change of smoking behavior among personnel. Regarding the possible association between smoking behavior change and TTM constructs, many studies have been conducted across different populations, especially in the western countries. Linda et al. showed that most subjects were in earlier stage of smoking behavior and three factors were identified as major contributors toward quitting smoking: high readiness, previous experience of smoking cessation barriers, and having the experience of smoking cessation [8]. Grima et al indicated that two hundred and nineteen $(57 \%)$ smokers had the intention to quit cigarette within the next six months and the process of change had an increasing trend across the stages [9]. Therefore, it is important to develop an adequate understanding about the factors related to smoking cessation and its maintenance. This study is based on TTM for proposing the appropriate interventions regarding the strongest predictor constructs to prevent and reduce smoking among personnel in Ardebil hospitals.

\section{Method}

This analytical study included a convenience sample of 200 current and former smoker 
personnel working at four hospitals in Ardabil, northwest of Iran. Prior to data gathering, permission was obtained from the institutional review board at the Ardebil university of medical sciences. The current study enjoyed a 2-stage sample design.

Stage 1: The first stage involved sample size determination. So the stage of change questionnaire was distributed among 834 male personnel at four Ardebil hospitals totally, 590 questionnaires were returned with the response rate of $70.74 \%$. Among the completed questionnaires, $220(37.28 \%)$ male personnel were identified as smokers (current or former) and met the study criteria.

Stage 2: Among the personell Who had the including criteria of the study , 200 individuals voluntarily enrolled in this study, so the TTM tools were distibuted among this population.

According to TTM, the inclusion criteria was smoking at least one cigarette during the past 30 days for smokers and quitting smoking within six month ago for none-smokers.

Stage of Change: Stage of change is a threequestion short form designed to assess the motivation of the individuals to quit smoking while categorizing them into one of the five stages of change depending on their willingness to quit in the next month or next six months.

Precontemplation, contemplation, and determination stages have been found to predict the attempts to quit, as well as cessation success between 1 and 6 months of followups. The perceived competence scale includes four items on a Likert scale. It reflects the participants' feelings about the competency to quit smoking from never true to always true. The higher scores indicate higher perceived competency to quit smoking. The perceived competence scores demonstrated an adequate reliability (alpha $>0.80$ ) [10].

Processes of Change Scale: The short form (20item) version of the original 40-item questionnaire of processes of change was used in this study to assess the TTM constructs (Fava etal 1991). Participants responded to two statements for each of 10 processes (experiential and behavioral), indicating their usage frequency of that process on a 5-point Likert scale (1=never, 5=repeatedly). In the present study, internal consistency for these 10 subscales was varied, ranging from $\mathrm{r}=0.40$ to $\mathrm{r}=0.80$ [11].

Decisional Balance Scale: The next construct of TTM was the decisional balance scale. In this study, the short form of the Decisional Balance Scale (DBS) was used. The decisional balance scale judges on the relative importance of both positive and negative aspects of the behavior change. Decisional balance scale reveals a pattern. During the pre contemplation phase, the positive aspects of the behavior overshadow the negative aspects of it. During the contemplation stage, the positive aspects and negative aspects appear as equal. During the determination and action stages of TTM, the negative aspects of the behavior outweigh the positive aspects of it. The smoking version of the DBS rates on a 5-point Likert scale (in which $1=$ not at all and 5=extremely) based on how each item is important on individuals decision to smoke. Internal consistency was measured by Cronbach's alpha and the coefficient was 0.87 for pros items of quit smoking and 0.90 for con items of quit smoking. Besides, both sets of items showed a strong predictive validity for future smoking behavior [12].

Self-efficacy/temptation: The final construct of TTM is self-efficacy/temptation. This construct describes the individual's confidence to continue with the positive behavior change. Particularly, the self-efficacy/temptation construct can depict the individual's confidence to continue with a positive behavior facing the temptation to return to his/her previous behavior. The temptation scale rates the individuals' feelings of temptation to smoke in each situation from 1 to $5(1=$ not at all tempted to $5=$ extremely tempted). The positive/social subscale for temptation had an internal consistency reliability alpha of 0.84 . The negative/attitude subscale for temptation had an alpha of 0.92 , and the addiction habit for temptation scale had an alpha of 0.80.[13] Approximately, each questionnaire took approximately 50 minutes to complete.

Descriptive statistics were used to assess 
demographic and smoking-related characteristics of the study participants. Besides, correlation analysis was performed to examine the relationships between variables. Furthermore, one way ANOVA analysis was used to test the effects of processes of change in the stage transition. Ordinal logistic regression analyses was also used to test the strongest predictor of stage of change. Data was screened for data-entry accuracy and assuring the assumptions of the statistical tests had been met. Differences with a probability of less than 0.05 were considered to be statistically significant. The SPSS-21 was used for the analyses.

First, the current study was approved by the research deputy of Ardebil University of Medical Sciences as well as the hospital managers. Then the questionnaires were distributed among hospital personnel. Verbal consent was obtained prior to data collection from the personnel who agreed to participate in the study and they were informed that their information is confidential.

\section{Results}

The mean age of the personnel who participated in the study was 38.4 years old and $92 \%$ of the participants were married. Besides, $12 \%$ of the participants had post graduate education. The monthly income for $75 \%$ of participant was more than seven million Rials. $38.5 \%$ of participants had started smoking at teenage and $25 \%$ of the subjects had smoker parents. Besides, $83 \%(n=166)$ of participants were current smokers and 17\% $(n=34)$ were former ones. Furthermore, the findings of stages of change was as follows: pre- contemplation $=37.0 \%$, contemplation $=$ $29.5 \%$, determination $=16.5 \%$, action $=6 \%$ and maintenance $=11 \%$ (Table 1$)$.

Table1 General characteristics of the study participants $(n=200)$

\begin{tabular}{lccc}
\hline Variable & Value & $\mathrm{n}$ & Percentage \\
\hline \multirow{3}{*}{ Education } & Diploma or less than diploma & 104 & 52.0 \\
& Bachelor & 72 & 36.0 \\
& Post graduate & 24 & 12.0 \\
\hline \multirow{2}{*}{ Income (monthly) } & Less than 7 mil rial & 111 & 55.5 \\
& Up than 7 mil rial & 89 & 44.5 \\
\hline \multirow{2}{*}{ Smoking status } & Former smoker & 34 & 17.0 \\
& Current smoker & 166 & 83.0 \\
\hline \multirow{4}{*}{ Stage of change } & Precontemplation & 74 & 37.0 \\
& Contemplation & 59 & 30 \\
& Preparation & 33 & 16.0 \\
& Action & 12 & 6.0 \\
Family smoking & Maintenance & 22 & 11.0 \\
& Parent & 50 & 25.0 \\
& Grandfather/grand mother & 15 & 7.5 \\
& Brother/sister & 21 & 10.5 \\
& All of above & 12 & 6.0 \\
& None of them & 102 & 51.0 \\
\hline \multirow{4}{*}{ Cigarettes (per day) } & 10 or less & 137 & 68.5 \\
& $11-20$ & 43 & 21.5 \\
& 21 - 30 & 9 & 4.5 \\
Marriage & 31 or more & 11 & 5.5 \\
\hline & Married & 184 & 92.0 \\
& Single & 16 & 8.0 \\
\hline
\end{tabular}

The results of correlation analysis indicated that the stages of change were significantly correlated with behavioral processes, pros of smoking, cons of smoking and self-efficacy $(\mathrm{p}<0.01)$. Behavioral processes were also significantly associated with experiential processes, pros of smoking, cons of smoking and self-efficacy $(\mathrm{p}<0.01$; Table 2$)$.
To assess the effects of processes of change on positive progressing stage of change, one-way Anova was used. The results showed that the samples used the behavioral processes such as stimulus control and counter conditioning to make a positive change in stages of change used (Table 3). 
Predictors of intention to quit smoking

Table2 Correlation matrix of stages of change, processes of change, decisional balance and self-efficacy

\begin{tabular}{|c|c|c|c|c|c|}
\hline Variable & $\begin{array}{l}\text { Stage of } \\
\text { change }\end{array}$ & $\begin{array}{l}\text { Experiential } \\
\text { processes }\end{array}$ & $\begin{array}{c}\text { Behavioral } \\
\text { processes }\end{array}$ & $\begin{array}{l}\text { Cons of } \\
\text { smoking }\end{array}$ & $\begin{array}{c}\text { Pros of } \\
\text { smoking }\end{array}$ \\
\hline \multicolumn{6}{|l|}{ Processes of change } \\
\hline Experiential processes & $0.680^{* *}$ & & & & \\
\hline Behavioral Processes & $0.260^{* *}$ & $0.001^{* *}$ & & & \\
\hline \multicolumn{6}{|l|}{ Decisional balance } \\
\hline Cons of smoking & $-0.55^{* *}$ & $0.001^{* *}$ & $0.001^{* *}$ & & \\
\hline Pros of smoking & $-0.20^{* *}$ & $-0.51^{* *}$ & $-0.36^{* *}$ & -0.026 & \\
\hline Self-efficacy & $-0.62^{* *}$ & $0.50^{* *}$ & $0.001^{* *}$ & $0.23^{* *}$ & $0.001^{* *}$ \\
\hline
\end{tabular}

Table 3 Evaluating the progress of change stages based on the processes of change among hospital staff working at Ardebil university of medical sciences in 2013

\begin{tabular}{|c|c|c|c|c|c|c|}
\hline $\begin{array}{l}\text { Stage of change } \\
\text { Process of change }\end{array}$ & $\begin{array}{l}\text { Pre contemplation } \\
\qquad \mathrm{M} \pm \mathrm{SD}\end{array}$ & $\begin{array}{l}\text { Contemplation } \\
\qquad \mathrm{M} \pm \mathrm{SD}\end{array}$ & $\begin{array}{l}\text { Preparation } \\
\qquad \mathrm{M} \pm \mathrm{SD}\end{array}$ & $\begin{array}{l}\text { Action } \\
\mathrm{M} \pm \mathrm{SD}\end{array}$ & $\begin{array}{l}\text { Maintenance } \\
\qquad \mathrm{M} \pm \mathrm{SD}\end{array}$ & $\begin{array}{l}\text { One-way } \\
\text { Anova } \\
\text { p-value }\end{array}$ \\
\hline Experiential & $27 \pm 8$ & $34 \pm 7$ & $31 \pm 9$ & $35 \pm 8$ & $40.09 \pm 7$ & 0.001 \\
\hline Behavioral & $26 \pm 8.09$ & $29 \pm 7$ & $28 \pm 6.09$ & $30 \pm 3$ & $37 \pm 7$ & 0.001 \\
\hline Consciousness raising & $5 \pm 2$ & $6 \pm 2$ & $6.09 \pm 2$ & $7 \pm 2$ & $8 \pm 1$ & 0.001 \\
\hline $\begin{array}{l}\text { Environmental } \\
\text { reevaluation }\end{array}$ & $5 \pm 2$ & $6 \pm 2$ & $6 \pm 2$ & $6 \pm 2$ & $8 \pm 2$ & 0.001 \\
\hline Self-reevaluation & $5 \pm 2$ & $7.01 \pm 2$ & $6 \pm 2$ & $7 \pm 2$ & $8 \pm 2$ & 0.001 \\
\hline Social liberation & $5 \pm 2$ & $6 \pm 2$ & $5 \pm 2$ & $7 \pm 2$ & $7 \pm 2.01$ & 0.001 \\
\hline Dramatic relief & $6 \pm 2.03$ & $7 \pm 2.03$ & $7.03 \pm 2.02$ & $6 \pm 1$ & $7 \pm 2$ & 0.025 \\
\hline Helping relationships & $5 \pm 2$ & $5 \pm 2$ & $5 \pm 2.07$ & $5 \pm 2$ & $7 \pm 2$ & 0.082 \\
\hline Self-liberation & $5 \pm 2$ & $7 \pm 1$ & $7.03 \pm 2$ & $8 \pm 1$ & $8 \pm 2$ & 0.001 \\
\hline Counterconditioning & $5 \pm 1$ & $4 \pm 2.01$ & $4 \pm 2.04$ & $5 \pm 1$ & $7 \pm 2$ & 0.001 \\
\hline $\begin{array}{l}\text { Reinforcement } \\
\text { management }\end{array}$ & $4 \pm 2$ & $5 \pm 2.09$ & $4 \pm 2$ & $4 \pm 2$ & $5 \pm 2.05$ & 0.025 \\
\hline Stimulus control & $4 \pm 2$ & $5 \pm 2$ & $6 \pm 2$ & $6 \pm 1$ & $8 \pm 2$ & 0.001 \\
\hline
\end{tabular}

Predictive power of TTM constructs in smoking cessation among Hospital Employees working at Ardebil university of medical sciences based on ordinal regression

The results of ordinal regression analysis to determine the predictive power of TTM constructs in smoking cessation revealed that the experiential processes of change, self-efficacy and behavioral processes of change were the strongest predictors of smoking cessation among hospital personnel working at Ardebil university of medical sciences (Table 4).

Table 4 TTM constructs prediction in smoking cessation among hospital staff working at Ardebil Medical Sciences University in 2013

\begin{tabular}{cccccccc}
\hline $\begin{array}{c}\text { Ordinal } \\
\text { regression }\end{array}$ & $\beta$ & Std. error & Wald & $\mathrm{df}$ & Sig. & \multicolumn{2}{c}{$95 \%$ Confidence interval } \\
\hline EXP & .067 & .020 & 10.0 & 1 & .001 & -0.027 & 0.001 \\
BP & .027 & .025 & 1.000 & 1 & .001 & -.021 & .075 \\
DB & -.041 & .030 & 1.000 & 1 & .001 & .001 & 0.019 \\
SELFE & -.059 & .018 & 11.000 & 1 & .001 & -.094 & 0.025 \\
\hline
\end{tabular}

Reduction in the score of self-efficacy (increase in the score of temptation) lead to the reduction of positive progress in the stages of change

\section{Discussion}

The present study performed a rigorous psychometric evaluation on a Persian version of TTM questionnaire (short form) for smoking cessation. In general, the results showed that this instrument was valid to measure smoking behavior change among hospital male personnel in Ardebil city. 
theory-based instruments are considered as an important prerequisite for any attempt to implement and evaluate health education/ promotion interventions. Therefore we believe that the findings of the current study could be helpful for those who are involved in tobacco control programs both at action level and research settings. This study demonstrates that the majority of participants were in the earlier stage of change and not willing to quit smoking. These results were consistent with previous studies like Saime erol \& Semra erdogan in which high school students were in earlier stages [14] and the study of Haddad et-al on Jordanian university students [8]. Besides, the study findings revealed that decisional balance, self-efficacy and processes of change are significantly correlated with the stage of change. These findings are consistent with previous studies that used TTM to test the smoking cessation among Korean young students [15]. However, Farmanbar et al found that only the processes of change were correlated with the stage of change [16]. The current study found that experiential processes of change, selfefficacy, and behavioral processes of change strongly predict the stage of change. Therefore, it is assumed that these TTM constructs can lead to positive progress in smoking cessation stages. Wagner, Burg, \& Sirois found that within the framework of TTM, behavioral processes of change was associated with advanced stages among adult smokers [17]. The results of oneway ANOVA analysis between the process of change and stage of change revealed that the participants according to their stages, used different processes of change. Besides, behavioral and experiential processes of change lead to the stage transition or positive progress in smoking cessation stages. The findings of the current study are consistent with a study which used TTM to test the smoking cessation among smokers in Rasht. Farmanbar. et al also found that behavioral processes of change were the strongest predictor of stage of change which resulted in stage progress of smoking cessation [16]. However, Ok Kyung Ham \& Jae Bok Yoo found the partial mediation of self- efficacy in the stage transition among Korean young student [15]. As well, Mazloomi et al. found that decisional balance mediate the relationship between the processes of change and stages of exercise behavior change which leads to stage transition [18].

Two limitations are noteworthy. The focus on an personnel community sample potentially limits the generalizability of the results from this study to other populations. Second, in this study the smoking status is assessed at follow-up by self-report rather than using a biochemical method. Although biochemical verification of smokers' status is often preferred, self-report is typically noted as valid. Future studies should attempt to increase the practicality of the instrument.

\section{Conclusion}

The current study revealed that readiness increase to quit smoking is significantly predicted by the mechanisms of self-efficacy and experiential process of change such as environmental reevaluation and behavioral process of change such as stimulus control and counter conditioning, which can lead to positive progress in the stage of change among smokers and smoking quitters. Future studies should explore the effects of smoke cessation interventions which are based on TTM.

\section{Acknowlendgments}

The authors gratefully acknowledge the all samples that assisted the research team.

\section{Contributions}

Study design: SN

Data collection and analysis: SN , EKL

Manuscript preparation: FM

\section{Conflict of Interest}

"The authors declare that they have no competing interests."

\section{Funding}

The author (s) received no financial support for the research, authorship and/or publication of this paper. 


\section{References}

1- Aveyard P, Massey L, Parsons A, Manaseki S, Griffin C. The effect of transtheoretical model based interventions on smoking cessation. Soc Sci Med2009; 68(3): 397-403.

2- Meysamie A, Ghaletaki R, Haghazali M, et al. Pattern of tobacco use among the Iranian adult population: results of the national survey of risk factors of noncommunicable diseases (SuRFNCD-2007). Tob Control2010; 19(2): 125-8.

3- Herrmann D. TNS opinion \& social. special euro barometer-European comission. (2010). Available at URL: http://ec.europa.eu/health/tobacco/docs/ebs332 en.pdf. Accessed January 2010.

4- Haik N. History of the World Health Organization framework convention on tobacco control. Available at URL: http://www.who.int/tobacco/wntd/2009/en/index. html. Accessed July 1998.

5- Sharifi-Rad GhR, Charkazi A, Shahnazi H, Kouchaki GhM, Orouji MA, Ekrami Z. Smoking behavior among male student's bases on transtheoretical model. Journal of Fundamentals of Mental Health2012; 13(4): 386-95.

6- Prochaska AV. New development in smoking cessation. Chest2000;117:169-75.

7- Prochaska JO, Redding CA, Evers KE. The transtheoretical model and stages of change. In: Glanz K, Rimer BK, Lewis FM, eds. Health behavior and health education: theory, research, and practice. San Francisco: Jossey-Bass publisher; 2008. pp:135-59.

8- Haddad LG, Petro-Nustas W. Predictors of intention to quit smoking among Jordanian university students. Can J Public Health2006; 97(1): 9-13.

9- Girma E, Assefa T, Deribew A. Cigarette smokers' intention to quit smoking in dire dawa town ethiopia: an assessment using the transtheoretical model. BMC Public Health2010; 10: 320.

10- DiClemente CC, Prochaska JO, Fairhurst SK, Velicer WF, Velasquez MM, Rossi JS. The process of smoking cessation: an analysis of precontemplation, contemplation, and preparation stages of change. $J$ Consult Clin Psychol1991; 59(2): 295-304.

11- Prochaska JO, Velicer WF, DiClemente CC, Fava J. Measuring processes of change: applications to the cessation of smoking. J Consult Clin Psychol1988; 56(4): 520-8

12- Velicer WF, DiClemente CC, Prochaska JO, Brandenberg N. Decisional balance measure for assessing and predicting smoking status. J Pers Soc Psychol1985; 48(5): 1279-89.

13- Velicer WF, Diclemente CC, Rossi JS, Prochaska JO. Relapse situations and self-efficacy: an integrative model. Addict Behav1990; 15(3): 271-83.

14- Erol S, Erdogan S. Application of a stage based motivational interviewing approach to adolescent smoking cessation: the transtheoretical model-based study. Patient Educ Couns2008; 72(1): 42-8.

15- Ham OK, Yoo JB. Mediating effects of self-efficacy in the transtheoretical model among adolescent male smokers in Korea. Asian Nurs Res (Korean Soc Nurs Sci)2009; 3(1): 15-23.

16- Farmanbar R, Kazemnejad E, Rezasoltani P, Narimani S. Predictors of smoking cessation based on transtheoretical model among smokers in Pars-Khazar factory of Rasht in 2012. [dissertation]. Master degree in Nursing. Tehran: Shahid Beheshti college of Nursing and Midwifery 2012. pp: 280.

17- Wagner J, Burg M, Sirois B. Social support and the Trans theoretical Model: Relationship of social support to smoking cessation stage, decisional balance, process use, and temptation. Addict Behav2004; 29(5):1039-43. 18- Mazloomy S, Mohammadi M, Morovati Sharifabad MA, Falahzade H. A study of the decisional balance's role in exercise status among yazd's staff on the basis process of change model. Zahedan Journal of Research in Medical Sciences2009; 11(2): 57-65.

Copyright (C) 2016 ASP Ins. This open-access article is published under the terms of the Creative Commons Attribution-NonCommercial 4.0 International License which permits Share (copy and redistribute the material in any medium or format) and Adapt (remix, transform, and build upon the material) under the Attribution-NonCommercial terms. 